\title{
Evaluation of Torsional Oscillations in Paper Machine Sections
}

\author{
M. Aníbal Valenzuela, Senior Member, IEEE, John M. Bentley, Life Fellow, IEEE, and Robert D. Lorenz, Fellow, IEEE
}

\begin{abstract}
Torsional oscillations greatly affect performance and determine the bandwidth (BW) and damping of speed loops. Backlash due to gear reducers can also contribute to the triggering of oscillations, especially when the drive runs at very low load torque. This paper presents a detailed evaluation of these effects in typical electromechanical drive trains applied to paper machine sections. The cases evaluated consider torsional oscillations in two-mass and three-mass systems, and the effect of shaft diameter and length on the resonant frequencies of three typical paper machine sections. Time-domain response plots are evaluated to show the effect of speed response overshoot, reducer backlash, and step or ramp speed commands. Based on these results, mechanical design guidelines are given for the most significant drive train components in order to minimize torsional oscillations of the speed-controlled drive system.
\end{abstract}

Index Terms-Backlash, frequency-response analysis, jackshaft and reducer torsional stiffness, two- and three-mass modeling, resonance, torsional oscillations.

\section{INTRODUCTION}

A PAPER machine consists of different mechanical sections, each of them driven by one motor or an arrangement of one master motor and one or more slave (helper) drives, which are conventionally speed or torque regulated. Typical sections are represented by: fourdrinier, press, dryer, calender, and reel. In order to avoid damage to the sheet during formation, pressing, and dry-end finishing, all these sections must follow the master reference with minimum speed deviation, and deliver speed and torque nearly free of torsional oscillation.

A typical arrangement of a mechanical drive train is shown in Fig. 1. Main components are the driving motor, gear reducer, jackshaft, and the rolls. Depending on the kind of paper machine and the kind of mechanical section, great differences in the power requirements and section inertias can be found. Table I shows TAPPI power requirements (NRL and RDC) for three typical sections of a lightweight coated (LWC) paper machine [1]. The Size Press section consists of two 30-in-diameter rolls

Paper PID-04-24, presented at the 2004 IEEE Pulp and Paper Industry Conference, Vancouver, BC, Canada, June 27-July 1, and approved for publication in the IEEE TRANSACTIONS ON INDUSTRY APPLICATIONS by the Pulp and Paper Industry Committee of the IEEE Industry Applications Society. Manuscript submitted for review July 1, 2004 and released for publication November 19, 2004.

M. A. Valenzuela is with the Department of Electrical Engineering, University of Concepción, Concepción, Chile (e-mail: anivalenz@udec.cl).

J. M. Bentley is at 6239 Clearview Drive, Manitowish Waters, WI 54545 USA (e-mail: jmbentley@ centurytel.net).

R. D. Lorenz is with the Department of of Mechanical Engineering and the Department of Electrical and Computer Engineering, University of Wisconsin, Madison, WI 53706 USA (e-mail: lorenz@engr.wisc.edu).

Digital Object Identifier 10.1109/TIA.2005.844383

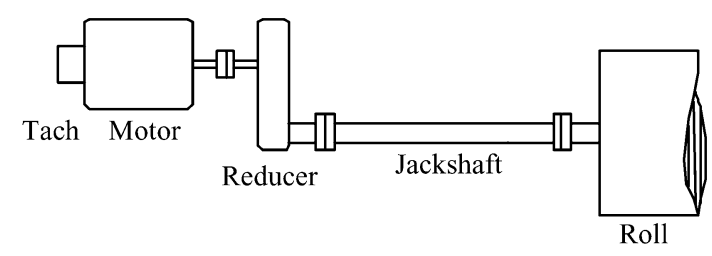

Fig. 1. Typical arrangement of a mechanical drive train.

TABLE I

SECTION CHARACTERISTICS

\begin{tabular}{|c|c|c|c|c|}
\hline \multirow{3}{*}{ SECTION } & \multicolumn{2}{|c|}{ TAPPI Power } & \multirow{2}{*}{$\begin{array}{c}\text { Moment of } \\
\text { Inertia } \\
\text { (@ roll) }\end{array}$} & \multirow{3}{*}{$\begin{array}{c}\text { Reducer } \\
\text { Gear Ratio }\end{array}$} \\
\hline & NRL & $\mathrm{RDC}$ & & \\
\hline & {$[\mathrm{KW}]$} & {$[\mathrm{KW}]$} & {$\left[\mathrm{Kg}-\mathrm{m}^{2}\right]$} & \\
\hline Size Press & 94.6 & 123.0 & 1057 & 6.2 \\
\hline Dryer & 83.2 & 179.2 & 76005 & $2 * 6.2$ \\
\hline Calender & 85.3 & 113.5 & 1961 & 5.06 \\
\hline
\end{tabular}

with a maximum nip pressure of $250 \mathrm{pli}$, and can be considered as a low-inertia section (connected load/motor inertia ratio approximately $20: 1$ ). The dryer section is formed by 1260 -in cylinders and 12 felt rolls, resulting in a large-inertia section (typical inertia ratio is 180 to $200: 1$ ). Finally, the calender section consists of three 24-in plain rolls and one hydraulically controlled crown roll, operating at $600 \mathrm{pli}$. It is a medium-range inertia section, with a load-to-motor inertia ratio of 80 to $100: 1$.

Mechanical drive trains include reducers, jackshafts, and associated couplings. Typical jackshaft lengths are between 2.5-3.5 m. They are the springiest elements of the system and mainly responsible for torsional oscillations during fast changes of the reference and/or load. Reducers, typically helical gear units, add extra torsional elasticity and backlash. The amount of backlash depends on the number of reduction stages of the reducer. For one-stage units, backlash is about $0.2^{\circ}-0.5^{\circ}$; and for two-stage gear units, is about $0.6^{\circ}-1.2^{\circ}$. Backlash effects show up during low load torque operation, and any time a decrease in the speed is commanded whereby the transition through zero torque could trigger torsional vibrations.

There is an extensive list of technical papers reported on torsional oscillations that propose different methods of controlling or reducing the oscillations [2]-[4]. Most of them are focused on servodrives with resonant frequencies in the range of $\geq 10^{2}$ $\mathrm{rad} / \mathrm{s}$, and the proposed mitigation techniques are based on notch [4], other kind of filters or by using different estimators [2]. Specifically, in [5], Ellis and Lorenz report a complete evaluation of seven different techniques, including both filters and 


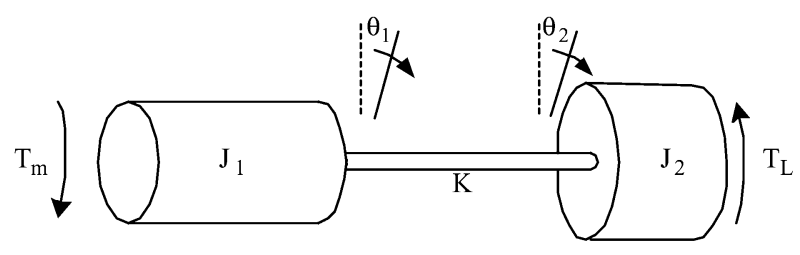

Fig. 2. Two-mass system with a torsional spring connection.

estimators, for a servo drive without considering backlash effects. The only references focused on torsional effects in paper machine drives are [6] and [7] by Bentley, including all the fundamentals, as well as field recordings and examples, with an emphasis on minimizing resonant torque amplitudes.

This paper will address the evaluation of torsional oscillations in the different mechanical sections of a paper machine, and points out the different mechanical issues and controller tuning considerations that should be followed to get minimum oscillation, which is also quickly damped out. The evaluation is done for the three typical sections reported in Table I, using two- and three-body models, and developing the frequency- and time-domain responses.

\section{Evaluation Using Two-Mass Model}

The simplest model that can be established to analyze torsional oscillations is the so-called two-mass model, consisting of two inertias $J_{1}$ and $J_{2}$ joined by an elastic shaft modeled by its torsional stiffness $K$ (see Fig. 2). When using this simple model, $J_{1}$ is assumed as the sum of the motor inertia and reducer inertia, $J_{2}$ is the inertia of the rolls (load inertia), and $K$ is the jackshaft torsional constant.

\section{A. Antiresonant and Resonant Frequencies}

Neglecting friction losses in motor and load, simple expressions can be found for the antiresonant $\left(f_{a r}\right)$ and resonant $\left(f_{r}\right)$ frequencies. These are

$$
\begin{aligned}
f_{a r} & =\frac{1}{2 \pi} \sqrt{\frac{K}{J_{2}}} \mathrm{~Hz} \\
f_{r} & =\frac{1}{2 \pi} \sqrt{K \frac{J_{1}+J_{2}}{J_{1} J_{2}}} \mathrm{~Hz} .
\end{aligned}
$$

Both expressions are proportional to the root of the torsional constant $K$. Also, it can be seen that the antiresonant frequency $f_{a r}$ depends only on inertia $J_{2}$,and, if inertia $J_{2}$ is much greater than $J_{1}$ (as in the dryer and calender sections), then the resonant frequency $f_{r}$ can be approximated by

$$
f_{r} \cong \frac{1}{2 \pi} \sqrt{\frac{K}{J_{1}}} \mathrm{~Hz} .
$$

This relationship shows that $J_{1}$ has the greater effect on $f_{r}$.

Table II summarizes the antiresonant and resonant frequencies and their magnitudes for the three sections of the LWC paper machine shown in Table I. These values include the effect of friction losses in the motor and load.

From Table II, it is possible to see that the resonant frequencies are much greater than the antiresonant frequencies. (A sit-
TABLE II

RESONANT FREQUENCIES AND MAGNITUDES

\begin{tabular}{lcccc}
\hline \hline \multirow{2}{*}{ SECTION } & \multicolumn{2}{c}{ Anti-resonance } & \multicolumn{2}{c}{ Resonance } \\
\cline { 2 - 5 } & $\mathrm{f}_{\mathrm{ar}}[\mathrm{Hz}]$ & Mag_f $_{\mathrm{ar}}[\mathrm{db}]$ & $\mathrm{f}_{\mathrm{r}}[\mathrm{Hz}]$ & Mag_f $_{\mathrm{r}}[\mathrm{db}]$ \\
\hline Size Press & 1.60 & -112.7 & 6.32 & 20.99 \\
Dryer & 0.45 & -136.7 & 5.59 & 17.22 \\
Calender & 2.00 & -138.6 & 16.60 & 25.54 \\
\hline
\end{tabular}

uation very different to what is often found in servodrives). For the size press, $f_{r}$ is about four times greater, and for the dryer $f_{r}$ is about 12 times greater. These differences can be explained because the ratio $f_{r} / f_{a r}$ is proportional to the root of inertia ratio $J_{2} / J_{1}$ as shown in (1) and (3). As expected, the lowest antiresonant frequency is for the dryer section, which has the highest load inertia.

These results are important because these frequencies greatly affect the BW that can be set in the speed controllers without producing instability problems.

\section{B. Shaft Parameters Sensibility}

According to (1) and (2), $f_{a r}$ and $f_{r}$ depend on the inertias $J_{1}$ (motor and reducer) and $J_{2}$ (rolls), and on the torsional stiffness $K$ of the jackshaft. As the motor and roll inertias are determined by process and power considerations, the only parameter that can be altered (optimized) in the mechanical design is the torsional stiffness constant $K$. For cylindrical shafts, $K$ is given by

$$
K=\frac{\pi E_{s}}{384}\left(\frac{D^{4}}{L}\right)
$$

where

$E_{s}$ steel shear modulus of elasticity;

$D$ jackshaft diameter;

$L$ jackshaft length.

According to (4), the most effective parameter for changing the torsional stiffness $K$ is the diameter $D$. As $f_{a r}$ and $f_{r}$ depend on the root of $K$, and $K$ depends on the fourth power of $D$, changes in diameter $D$ will produce changes in the antiresonant and resonant frequencies proportional to $D$ squared.

Figs. 3 and 4 show the effects of making changes of $\pm 10 \%$ and $\pm 20 \%$ in the diameter $D$, and the length $L$, of the jackshaft in the dryer section. Tables III and IV summarize the changes in $f_{a r}$ and $f_{r}$. For changes of $\pm 20 \%$ in diameter $D, f_{a r}$ changes from 0.29 to 0.65 , and $f_{r}$ changes from 3.58 to 8.05 . As expected, changes in length $L$ produce relatively minor variations of $f_{a r}$ and $f_{r}$.

These results show that in the mechanical design of the indrives, shaft lengths should be as short as possible, and that a $20 \%$ increase in shaft diameter will produce an increase of $44 \%$ in $f_{a r}$ and $f_{r}$.

\section{Time Responses to Step Commands}

The time-domain response of the drive systems to step commands depends upon the speed controller tuning and the resonant frequency of the drive train. 


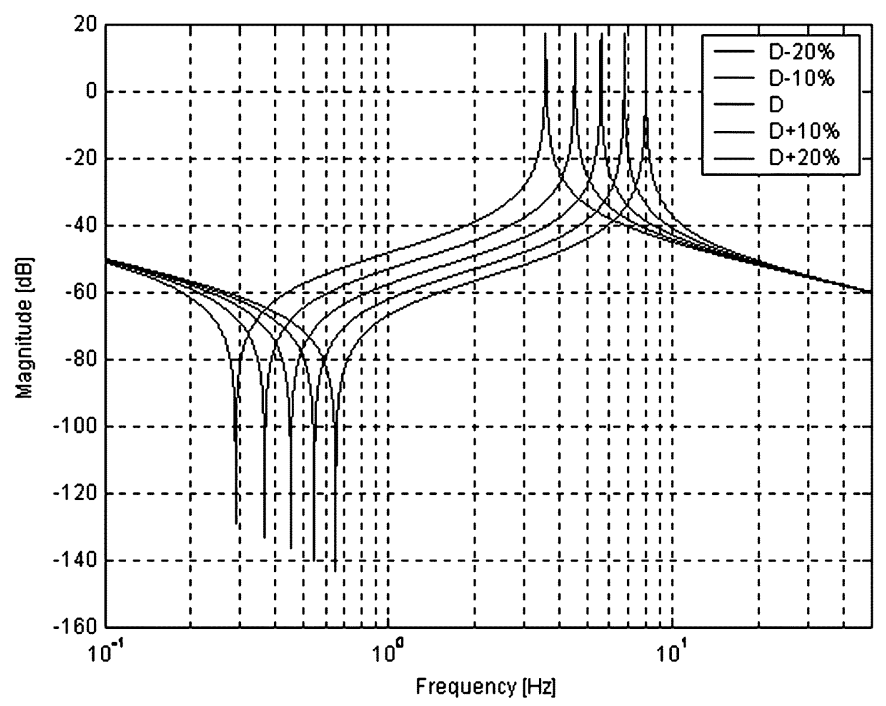

Fig. 3. Effect of variations of diameter $D$ of the jackshaft.

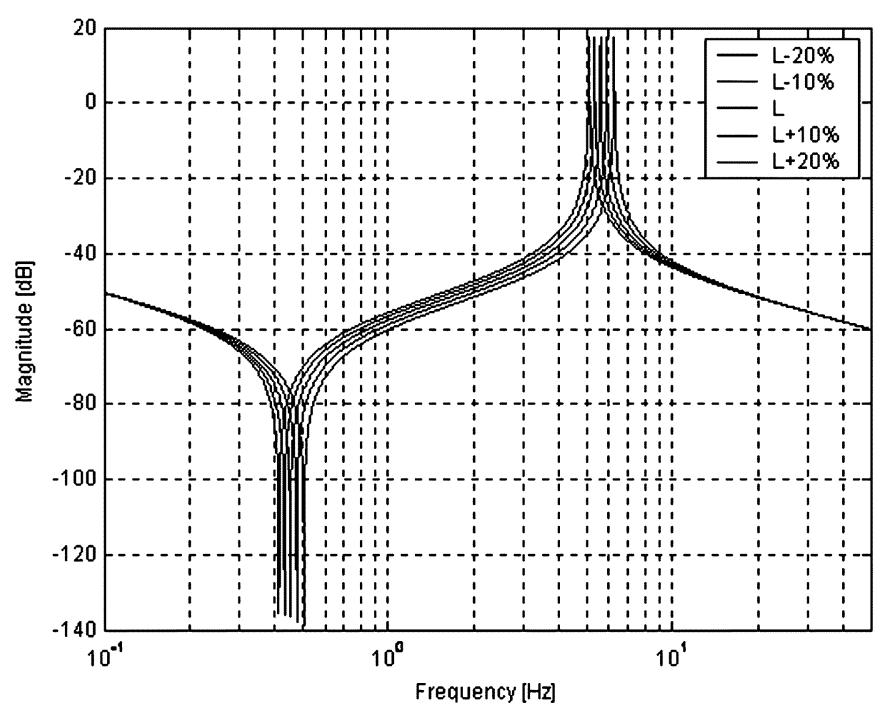

Fig. 4. Effect of variations of length $L$ of the jackshaft.

TABLE III

EFFECT OF DiAMETER $D$ VARIATIONS ON ANTIRESONANT AND RESONANT FREQUENCIES

\begin{tabular}{lccccc}
\hline \hline & $D-20 \%$ & $D-10 \%$ & $D$ & $D+10 \%$ & $D+20 \%$ \\
\hline$f_{\text {ar }}[\mathrm{Hz}]$ & 0.29 & 0.37 & 0.45 & 0.55 & 0.65 \\
$\mathrm{f}_{\mathrm{r}}[\mathrm{Hz}]$ & 3.58 & 4.53 & 5.59 & 6.77 & 8.05 \\
\hline
\end{tabular}

TABLE IV

EFFECT OF LENGTH $L$ VARIATIONS ON ANTIRESONANT AND RESONANT FREQUENCIES

\begin{tabular}{lccccc}
\hline \hline & $\mathrm{L}-20 \%$ & $\mathrm{~L}-10 \%$ & $\mathrm{~L}$ & $\mathrm{~L}+10 \%$ & $\mathrm{~L}+20 \%$ \\
\hline $\mathrm{f}_{\mathrm{ar}}[\mathrm{Hz}]$ & 0.51 & 0.48 & 0.45 & 0.43 & 0.42 \\
$\mathrm{f}_{\mathrm{r}[\mathrm{Hz}]}$ & 6.25 & 5.90 & 5.59 & 5.33 & 5.11 \\
\hline
\end{tabular}

By its nature, a step command excites the drive system controller momentarily with all frequencies making up the Fourier series for a step function. Consequently, the system is commanded to respond to all frequencies from the very highest at the initiation of the step to the final steady-state new value at
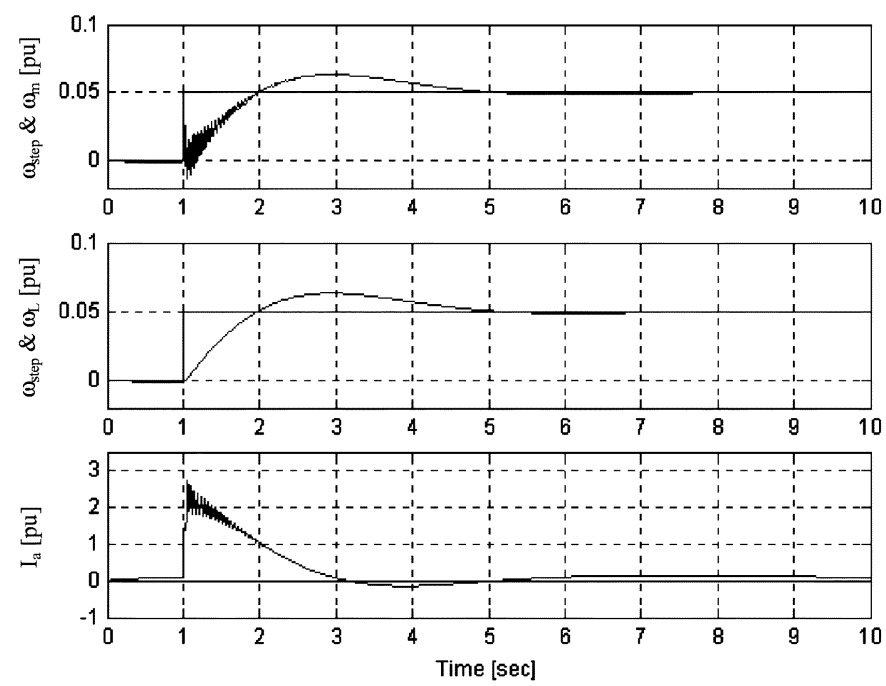

Fig. 5. Time-domain response to $5 \%$ step command of calender section (two-mass model, $15 \%$ overshoot).
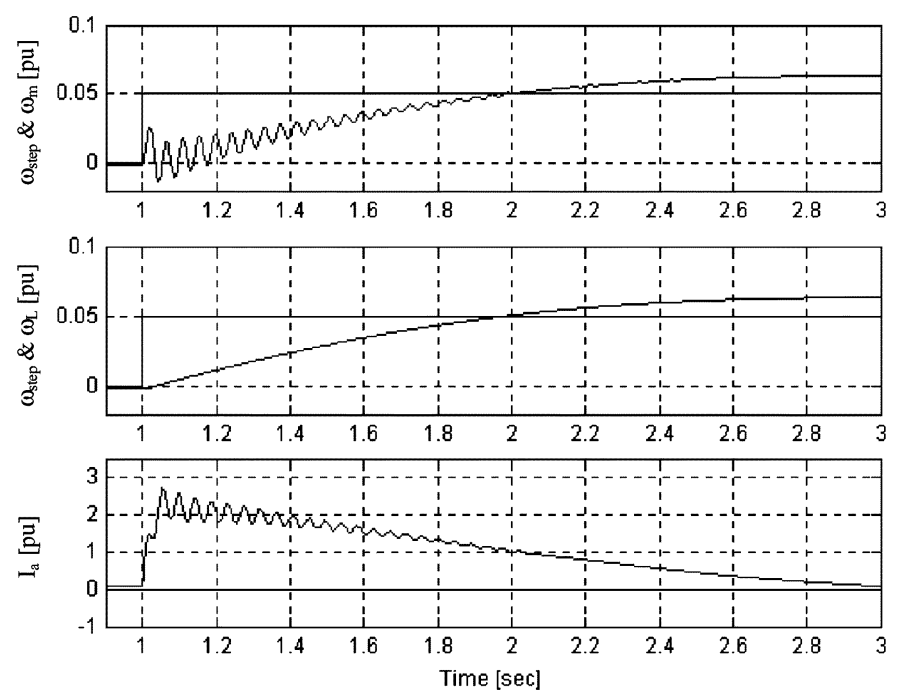

Fig. 6. Initial zoom of time response to $5 \%$ step command of calender section (two-mass model, 15\% overshoot).

the end of the transient. An appropriately tuned speed loop BW will have its "crossover frequency" well below the resonant frequency, assuring that the gain at resonant frequency is below unity (or zero $\mathrm{dB}$ ) and, therefore, the transient oscillations resulting from this resonance will be damped satisfactorily by the controller.

Figs. 5-8 show calender section response to 5\% step commands, $\omega_{\text {step }}$, for two different sets of the speed controller tuning, modeling the drive train as a two-mass system with an ideal reducer without backlash. Figs. 5 and 7 show all the transient responses, and Figs. 6 and 8 show zooms of the three first seconds of time responses. The speed controller tuning selected in Figs. 5 and 6 give a 15\% overshoot; and the settings selected in Figs. 7 and 8 give a critically damped speed response without overshoot.

From the waveforms of the motor speed $\omega_{m}$ and roll speed $\omega_{L}$ it can be seen that because load inertia is much higher than motor inertia, roll speed is almost free of torsional oscillations, 

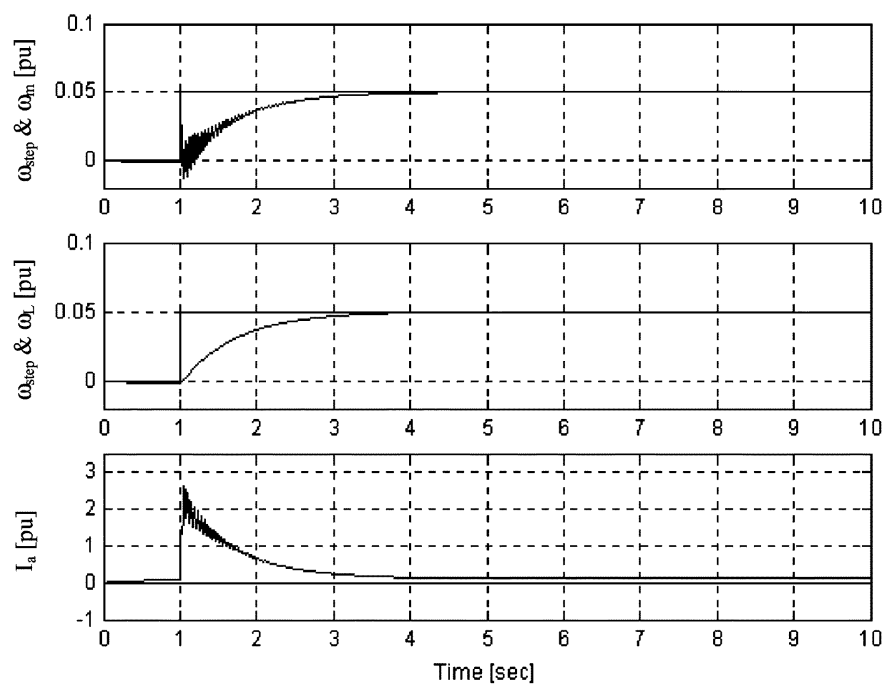

Fig. 7. Time-domain response to $5 \%$ step command of calender section (two-mass model, without overshoot).
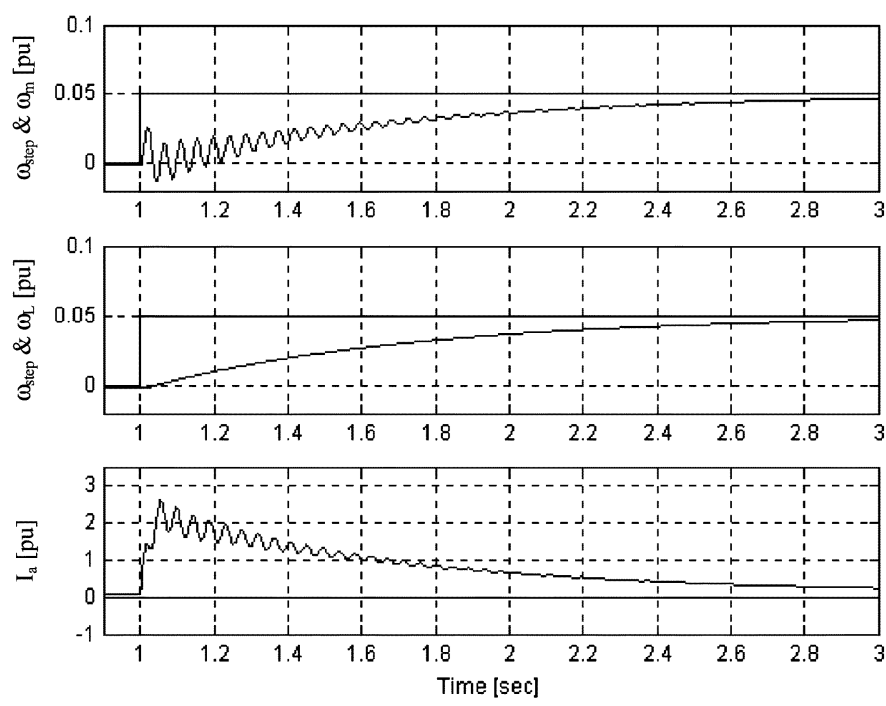

Fig. 8. Initial zoom of time response to 5\% step command of calender section (two-mass model, without overshoot).

and all the speed oscillations show up at the motor end. Note that the motor load current $I_{a}$ exhibits these oscillations as well, indicating that the motor torque is being excited by the control system as a result of the torsional speed oscillation. These oscillations last about $1 \mathrm{~s}$ and after that, the system behaves as a rigid body. If speed BW (crossover frequency) is indiscriminately set to higher values, system response will become less stable, and sustained damaging resonance-producing torques will likely occur.

Responses shown in Figs. 7 and 8 (without overshoot) can be considered well-behaved. Time-domain responses with overshoot, such as those shown in Figs. 5 and 6, are not appropriate in many instances, as will be shown in Section IV.

\section{Evaluation Using A ThreE-MASS MODEL}

The effect of the high-speed (HS) shaft stiffness and the reducer inertia can be explored using a three-mass model (see Fig. 9). Now, $J_{1}, J_{2}$, and $J_{3}$ are the motor, reducer, and roll iner-

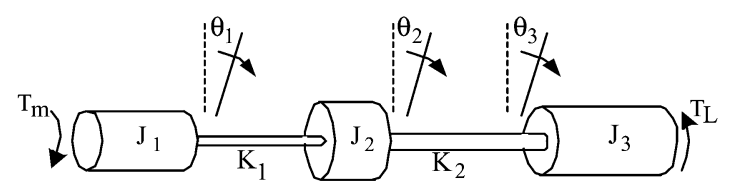

Fig. 9. Three-mass system with two spring connections.

TABLE V

Resonant Frequencies for Size Press SECTION (ThreE-MASs Model)

\begin{tabular}{lcccc}
\hline \hline \multirow{2}{*}{ SECTION } & $\mathrm{f}_{\text {ar1 }}$ & $\mathrm{f}_{\mathrm{r} 1}$ & $\mathrm{f}_{\mathrm{ar} 2}$ & $\mathrm{f}_{\mathrm{r} 2}$ \\
\cline { 2 - 5 } & {$[\mathrm{Hz}]$} & {$[\mathrm{Hz}]$} & {$[\mathrm{Hz}]$} & {$[\mathrm{Hz}]$} \\
\hline Size Press & 1.59 & 6.30 & 159.5 & 178.1 \\
\hline
\end{tabular}

tias, and $K_{1}$ and $K_{2}$ are the torsional stiffnesses of the HS shaft and jackshaft, respectively.

\section{A. Antiresonant and Resonant Frequencies}

For the three-mass model two pairs of antiresonant/resonant frequencies show up. Table $\mathrm{V}$ shows the corresponding values for the size press section.

The low pair of antiresonant and resonant frequencies is almost the same as found using the two-mass model. The high-frequency antiresonant/resonant pair that shows up using the threemass model is related to the torsional oscillations between the motor inertia $\left(J_{1}\right)$ and the reducer inertia $\left(J_{2}\right)$ due to the HS shaft elastic constant. For the size press section this resonant pair is located around $170 \mathrm{~Hz}$. This high value is due to the fact that HS shafts of the motor and reducer are much stiffer than the jackshaft, because of their shorter lengths (around 0.5-0.6 m), and their "overdesign" to carry overhung loading due to pinion gear support in the reducer, and the rotor support in the motor.

\section{B. Shaft Parameter Sensibility}

Most sensitive parameters are the diameters $D_{1}$ and $D_{2}$ of the HS shaft and jackshaft, respectively. Figs. 10 and 11 show the frequency responses of the size press section during changes of $\pm 10 \%$ and $\pm 20 \%$ of diameters $D_{1}$ and $D_{2}$, respectively. As expected, changes in $D_{1}$ (HS shaft) affect the $f_{a r 2} / f_{r 2}$ pair, and changes in $D_{2}$ (jackshaft) affect the $f_{a r 1} / f_{r 1}$ pair in the same way shown in Section II-B.

\section{EVALUATION OF THE EFFECT OF BACKLASH}

One important characteristic of the reducers not yet included is backlash. For helical gear units, such as those used in paper machine drive trains, the amount of backlash depends on the number of stages of the reducer, varying from $0.2^{\circ}$ to $0.5^{\circ}$ for one-stage reducers, and from $0.6^{\circ}$ to $1.2^{\circ}$ for two-stage units. The actual value is determined by the free movement between mating gear teeth at the pitch line between each gear set within the reducer. This movement is summed up as degrees of the pinion shaft rotation, measured with the low-speed output shaft locked. Certain types of nonrecommended couplings also exhibit detrimental backlash and, if used, must also be taken into account.

Backlash effects show up during the starting of paper machine sections, and during torque reversals in the drive train. Torque 


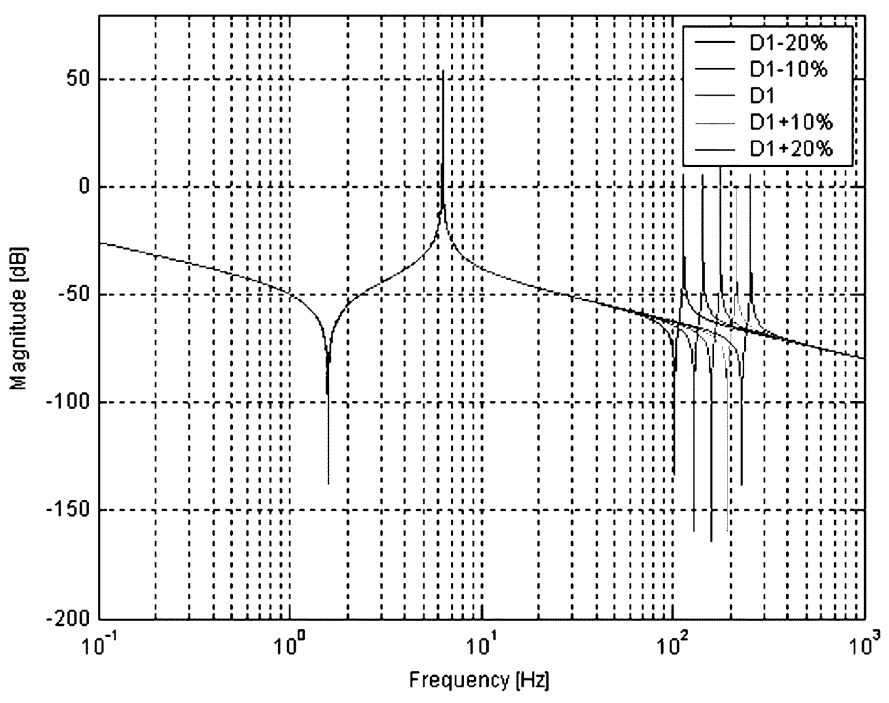

Fig. 10. Frequency response during changes of HS shaft diameter.

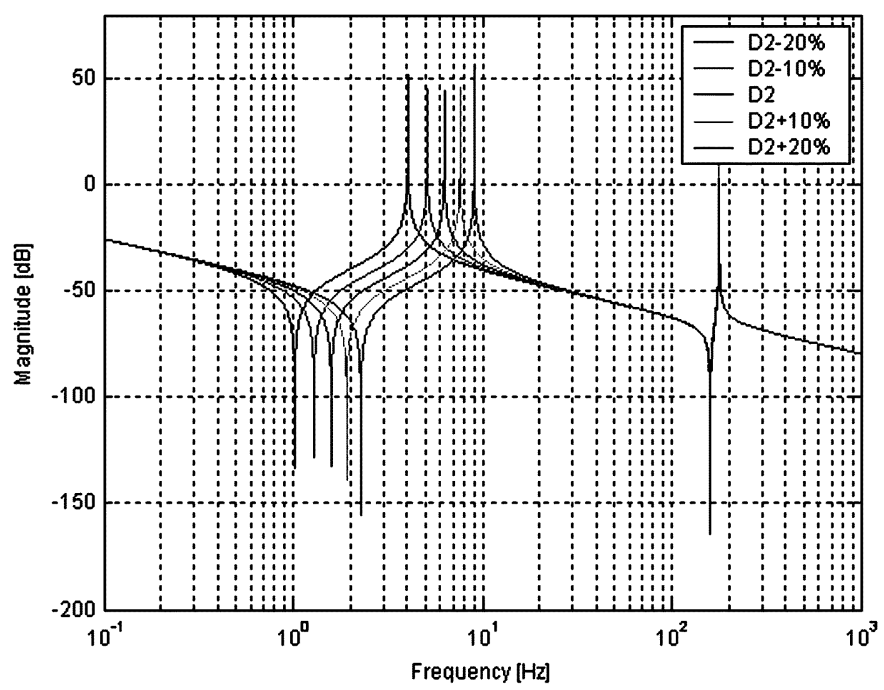

Fig. 11. Frequency response during changes of jackshaft diameter.

reversals can be produced by lowering of the speed reference. Also torque reversal may occur during low load torque operation when the downstream section pulls the sheet, forcing the torque to negative values. This condition is likely to show up in the last dryer section when the sheet tension reference in the calender is set too high.

\section{A. Backlash Modeling}

The model of a gear, considering the backlash effect, assumes the existence of a total backlash $\delta$ and a gear torsional stiffness, $K_{g}$, resulting in a center deadband zone bounded by linear zones as shown in Fig. 12.

A frequency-domain model of an electromechanical train involving backlash can be developed by application of the describing function method [3]. For any nonlinear element, the describing function is the transfer function corresponding to the fundamental component of the Fourier expansion. This method can be used for treating any nonlinear system as long as its response to a sinusoidal input is dominated for the first harmonic. Using this method it is possible to plot the frequency response

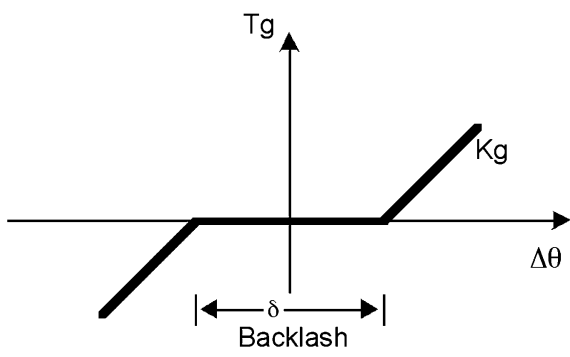

Fig. 12. Gear model considering backlash effect.

of the system in a similar way to that done in linear systems. The transfer function gain of the backlash is [3]:

$$
N(R)=\frac{2}{\pi} K_{g}\left(\frac{\pi}{2}-\sin ^{-1}(R)-R \sqrt{1-R^{2}}\right)<0^{\circ}
$$

where

$$
R=\frac{\delta}{2 A}
$$

where $A$ is the amplitude of the input signal $\Delta \theta$.

Plotting the describing function gain versus the inverse of $R$ it can be seen that the gain decreases from 1 to 0 as $R$ approaches 1 . Therefore, the presence of backlash in the reducer is equivalent to a variable gain $(0 \leq G \leq 1)$ acting on the gear gain of the linear region, $K_{g}$.

\section{B. Time-Domain Response Including Backlash}

Fig. 13 shows the complete model of the drive train of a typical section of a paper machine. The mechanical train is modeled as a two-mass system and a reducer with backlash. The drive is modeled with an inner current (torque) loop and external speed loop with speed feedback from the motor.

Using the same speed controller settings that give $15 \%$ overshoot (see Figs. 5 and 6) the two-mass calender section now including a $1^{\circ}$ backlash is evaluated. Fig. 14 shows time-domain response of motor and rolls speeds, motor current, shaft torque $T_{\text {shaft }}$, and the difference of angular position Delta between the pinion and the gear in the reducer. Figs. 15 and 16 show zoomed views of the same variables at the beginning of the starting transient and during the first shaft torque reversal.

Comparing the waveforms of Figs. 5 and 6 it can be seen that amplitudes of the initial oscillations are, in fact, reduced. This is explained because of the small delay introduced by backlash in getting the rolls effectively coupled to the drive.

Fig. 15 illustrates in detail the initial transient. At $t=1 \mathrm{~s}$, a $5 \%$ step command is applied and the motor starts to move.

Between 1.005-1.010 s the load gear remains uncoupled to the pinion, while the motor side and pinion approaches the loadside gear. Right after $1.010 \mathrm{~s}$, variable Delta reaches $0.5^{\circ}$ (half of backlash), and the pinion contacts the gear and the load becomes coupled to the motor.

For this evaluation, the speed controller response has been tuned to permit overshoot. At $t=3.2 \mathrm{~s}$, the motor and roll speeds reach their maximum values and start to fall. As the drive is assumed unloaded (load torque equals 0.1 p.u.), shaft torque through the drive train reverses its direction, causing the backlash to switch directions. Fig. 16 shows that in the interval from 


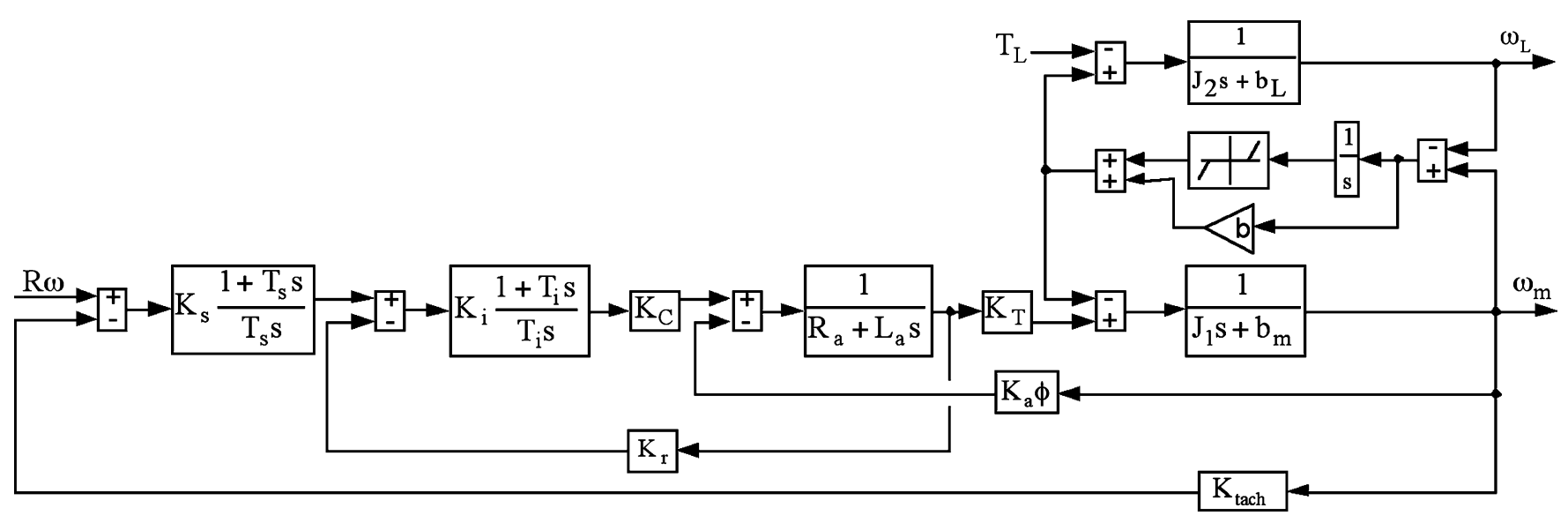

Fig. 13. Complete model of two-mass system with backlash and control loops.

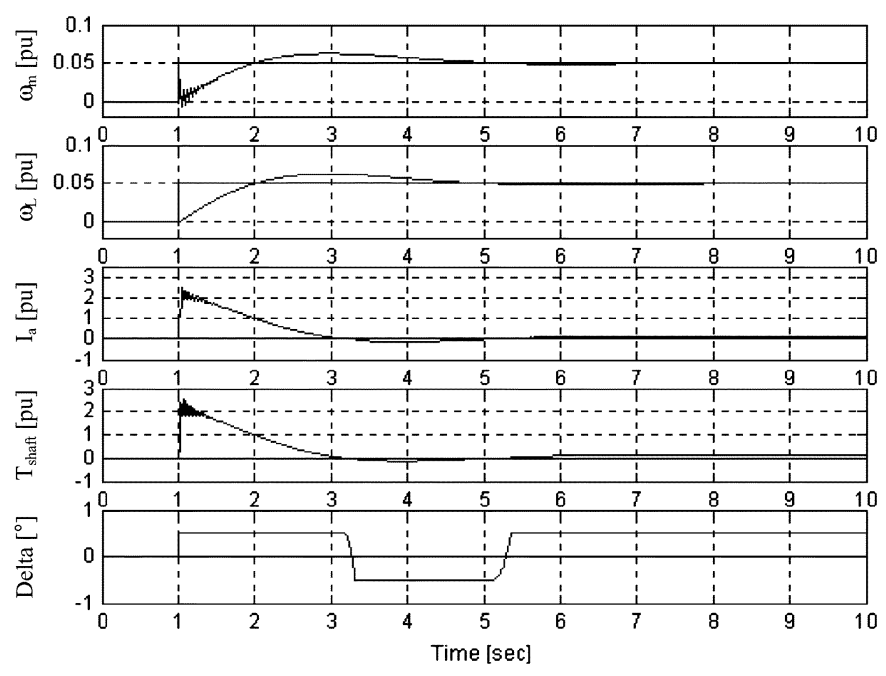

Fig. 14. Time-domain response to 5\% step command of calender section with backlash (two-mass model, $15 \%$ overshoot).

3.2 to $3.31 \mathrm{~s}$, the load becomes uncoupled from the drive, the shaft torque remains at zero, and variable Delta changes from $0.5^{\circ}$ to $-0.5^{\circ}$. After this, the load is again coupled to the drive, which then forces it to lower speed.

Fig. 14 shows that at $5.2 \mathrm{~s}$ the shaft torque reverses back to positive values and backlash again switches directions. It is important to notice that these two shaft torque reversals, along with the related backlash direction switching, are produced by the combination of speed response with overshoot and low load torque. The initial oscillations, due to jackshaft torsional loading, do not produce backlash direction switching because during this interval the motor is developing a high torque to accelerate the load inertia.

\section{DESIGN CONSIDERATIONS AND Mitigation TeCHNIQUES}

\section{A. Use of Hollow Shafts}

The most important design consideration in order to reduce torsional oscillations is to build the mechanical drive train with stiffer shafts. As concluded in Section II-B, the shaft diameter is the most sensitive parameter that affects the shaft stiffness $K$.

Although oversizing the jackshaft diameter yields a stiffer shaft (20\% increase in $D$ produce $44 \%$ increase in constant $K$ ),
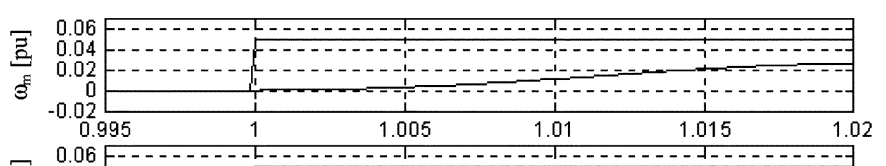

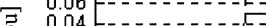
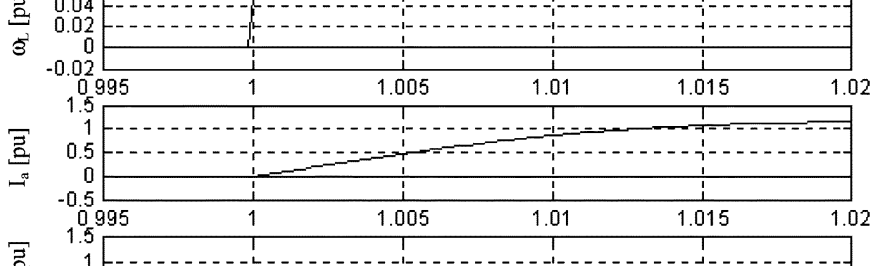

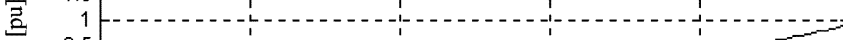
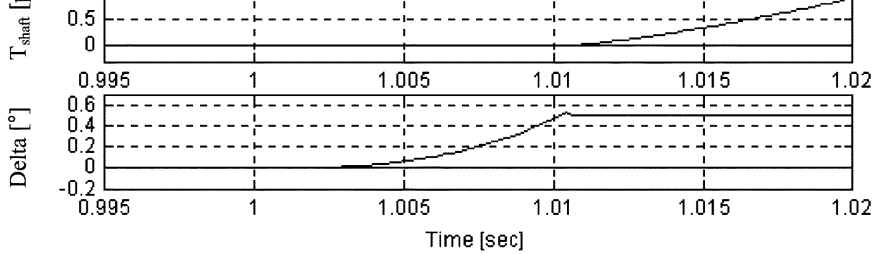

Fig. 15. Zoom view of the time-domain response to $5 \%$ step command of calender section with backlash (two-mass model, $15 \%$ overshoot).

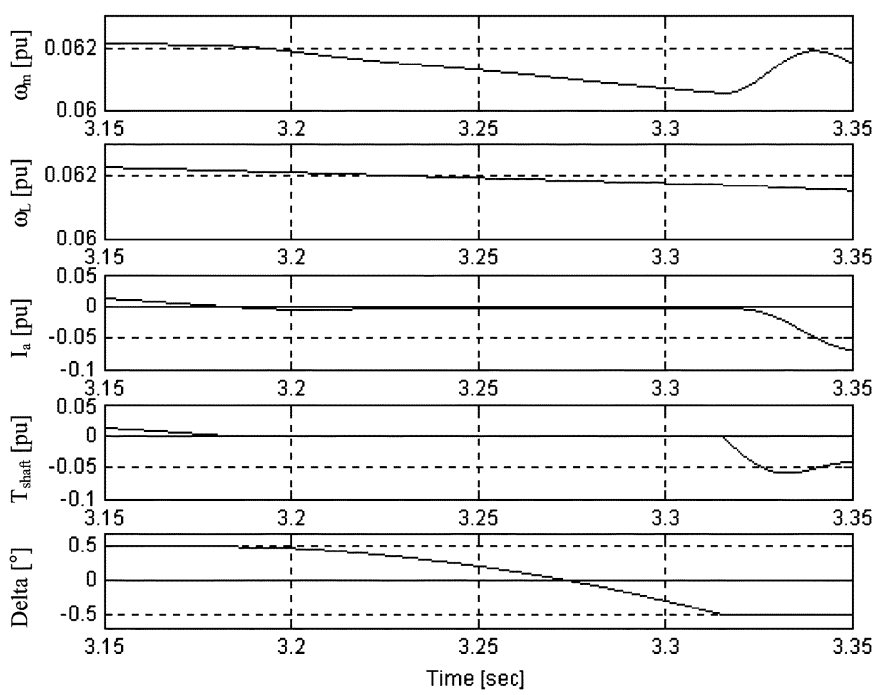

Fig. 16. Zoom view during first torque reversal of calender section with backlash (two-mass model, $15 \%$ overshoot).

it could create problems. Specifically, an oversized diameter $D$ will increase the shaft weight (and cost), and depending on the 


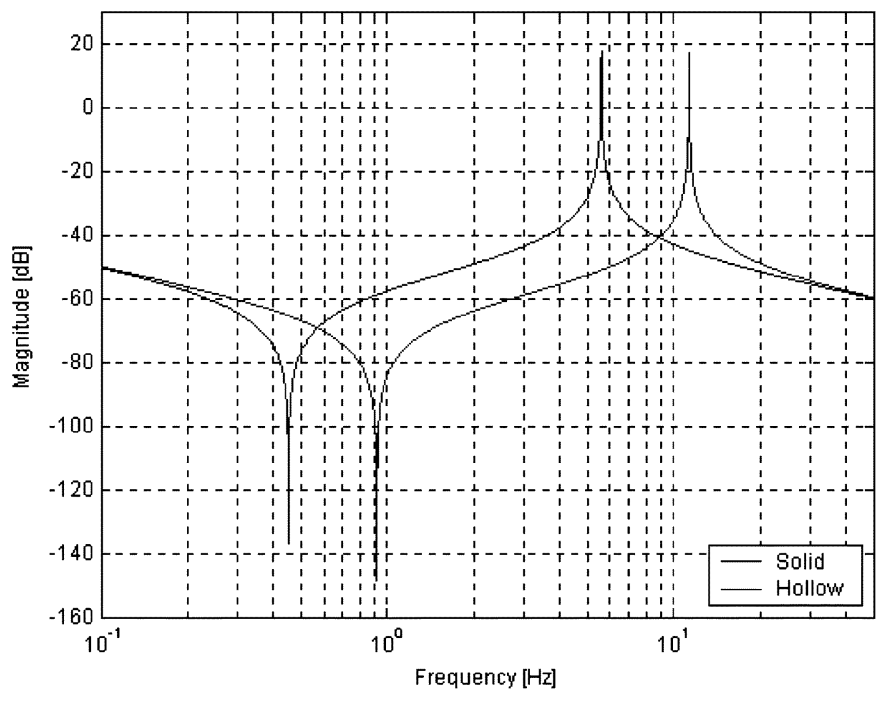

Fig. 17. Effect of using a hollow shaft in frequency response.

TABLE VI

COMPARISON OF RESONANT FREQUENCIES FOR SOLID AND HOLLOW SHAFTS

\begin{tabular}{lcc}
\hline \hline & Solid shaft & Hollow shaft \\
\hline $\mathrm{f}_{\mathrm{ar}}[\mathrm{Hz}]$ & 0.45 & 0.92 \\
$\mathrm{f}_{\mathrm{r}}[\mathrm{Hz}]$ & 5.59 & 11.35 \\
\hline
\end{tabular}

shaft length, could create some lateral vibration problems in the shaft.

A better solution is to use hollow shafts, which produce an increase in the torsional stiffness $K$, without necessarily increasing the shaft weight. For a cylindrical hollow shaft, of inner diameter $d$, the shaft torsional stiffness is given by

$$
K=\frac{\pi E_{s}}{384}\left(\frac{D^{4}-d^{4}}{L}\right)
$$

Fig. 17 shows the effect of using a hollow shaft in the dryer section and Table VI compares the antiresonant and resonant frequencies for the solid and hollow shafts. The specified hollow shaft has the same weight as the solid shaft and its outer diameter is $200 \mathrm{~mm}$, compared to the $125 \mathrm{~mm}$ diameter of the solid shaft.

According to Table VI, using this hollow shaft, $f_{a r 1} / f_{r 1}$ have been increased $100 \%$ of their original values (compared to $44 \%$ increase for a $20 \%$ oversizing of the jackshaft diameter).

The use of a hollow shaft is a powerful mechanical design tool that is extensively used in high-power and high-inertia sections of paper machines. In regard to drive performance, the use of hollow shafts in high-inertia sections yields an increase of the resonant frequency of these sections, therefore permitting higher BW in the speed controllers, which in turn improves the coordinated dynamic performance of the different mechanical sections.

\section{B. Effect of Overshoot of Speed Response}

Section IV-B explained that overshoot in speed response could produce backlash direction switching in the reducer during step reference commands with low load. In order to

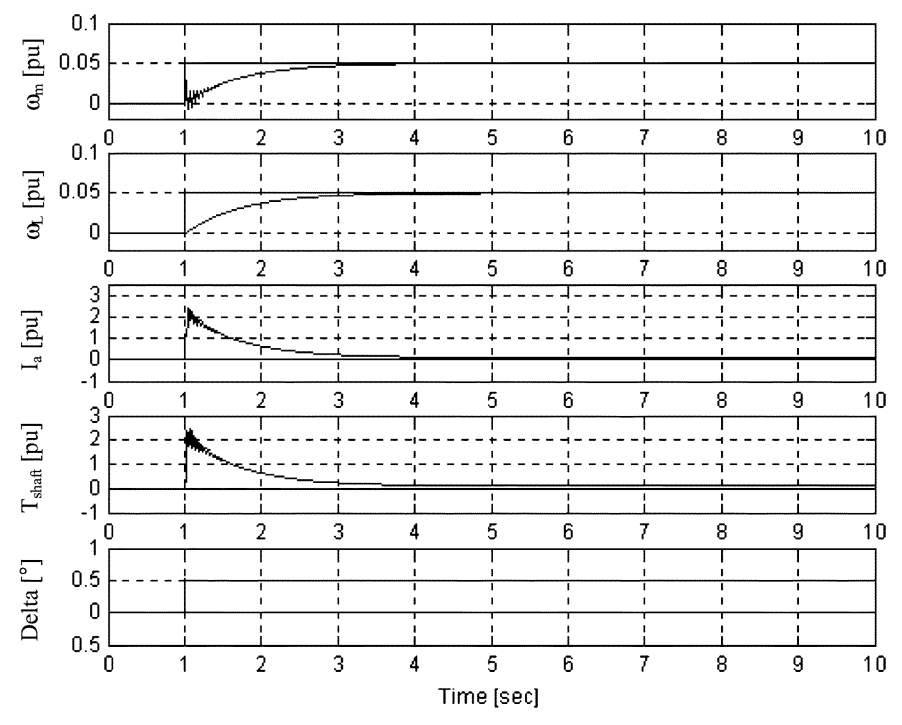

Fig. 18. Time-domain response to a 5\% step command of calender section with backlash (two-mass model, speed response without overshoot).
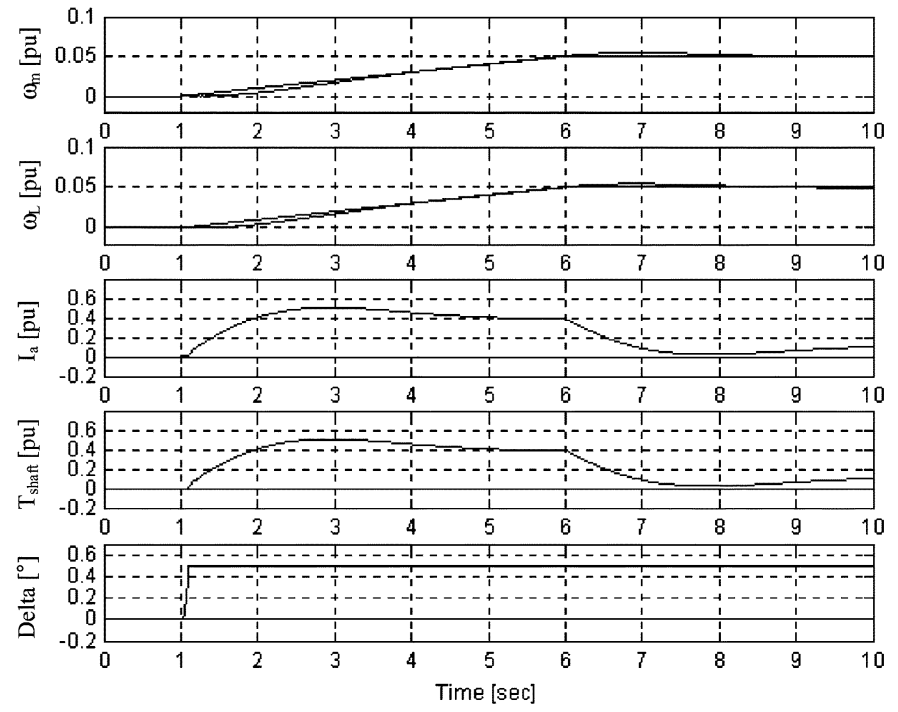

Fig. 19. Time-domain response to a 5\%, 5-s ramp command of calender section with backlash (two-mass model, speed response with 15\% overshoot).

avoid these disturbances, the usual practice is to set the speed response to critically damped response, without overshoot.

Fig. 18 shows the transient response of the calender section to a 5\% step reference command using the same settings of Figs. 7 and 8 (speed response without overshoot). As shown in this figure, there are no $T_{\text {shaft }}$ reversals during the transient, although the section is assumed to have a very low $10 \%$ load.

This result shows that an appropriate design criteria for speed controller tuning in paper machine sections is to get critically damped responses. This is especially useful in dryer sections.

\section{Use of Ramp Signals}

As mentioned earlier, step signals $\omega_{\text {step }}$ excite the drive controllers over a wide range of frequencies, therefore, transient response to step commands will include oscillations at the resonant frequency, regardless of its value. These oscillations normally will decay quite quickly according to the damping effect 
at this frequency, unless the speed controller BW settings are improperly set too high, thus causing sustained oscillation at the resonant frequency.

One important way of getting rid of these oscillations caused by the step reference commands is to use ramp reference commands with ramp time below the resonant frequency. As is well known, ramp references are also beneficial in reducing current peaks during command changes and are typically used in master reference changes.

Fig. 19 shows the ramp response of the calender section for a 5\% 5-s reference using the controller settings that allows $15 \%$ overshoot. It can be seen that the response is free of torsional oscillations and there are no shaft torque reversals that could produce backlash direction switching. Therefore, the use of ramp shape commands (especially S-ramp) is a very powerful tool to prevent torsional oscillations as well as backlash direction switching in paper machine sections.

\section{CONCLUSION}

Modeling and evaluation of typical paper machine sections have shown that torsional oscillations are an important issue that needs to be considered and properly handled in the design and tuning procedures of these drives. The most torsionally elastic elements in the drive chain are the jackshafts, and two-mass models are usually accurate enough to predict section dynamic performance with regard to torsional vibration.

Gearbox backlash effects show up during shaft torque reversals. These could be transient reversals occurring during overshoot of speed responses, or during normal regenerative operation of the sections where the motor torque required is near zero, or negative. Special attention should be directed to the last dryer sections, where sheet tension could produce a regenerating condition with unwanted backlash direction switching.

In order to get a well-behaved transient response, essentially free of oscillations, the following design considerations and controller setting criteria should be seriously considered.

- Use hollow, or oversized, jackshafts in high-inertia sections, which yield a stiffer system. Include oversize highquality zero-backlash couplings with these shafts. Avoid the use of U-joints and splined shafts insofar as possible.

- Use single-reduction high-quality oversized gear reducers, or direct-connected motors if practical.

- Design speed loop responses without overshoot.

- Use ramp reference signals instead of step references, even for auxiliary signals, setting the ramp time not only with current-limiting criteria, but also with frequency resonance criteria.

\section{REFERENCES}

[1] M. A. Valenzuela, J. M. Bentley, and R. D. Lorenz, "Sensorless tension control in paper machines," IEEE Trans. Ind. Appl., vol. 39, no. 2, pp. 294-304, Mar./Apr. 2003.

[2] R. Dhaouadi, K. Kubo, and M. Tobise, "Analysis and compensation of speed drive systems with torsional loads," IEEE Trans. Ind. Appl., vol. 30, no. 3, pp. 760-766, May/Jun. 1994.

[3] S. N. Vukosavic and M. R. Stojic, "Suppression of torsional oscillations in a high-performance speed servo drive," IEEE Trans. Ind. Electron., vol. 45, no. 1, pp. 108-117, Feb. 1998.
[4] P. Schmidt and T. Rehm, "Notch filter tuning for resonant reduction in dual inertia systems," in Conf. Rec. IEEE-IAS Annu. Meeting, Phoenix, AZ, 1999, pp. 1730-1734.

[5] G. Ellis and R. D. Lorenz, "Resonant load control methods for industrial servo drives," in Conf. Rec. IEEE-IAS Annu. Meeting, Rome, Italy, 2000, pp. 1438-1445.

[6] J. M. Bentley, "Electromechanical drive train design and application. Part I," presented at the TAPPI Paper Machine Drives Short Course, Atlanta, GA, 1999.

[7] - "Electromechanical drive train design and application. Part II," presented at the TAPPI Paper Machine Drives Short Course, Atlanta, GA, 1999.

[8] G. J. Thaler and M. P. Pastel, Analysis and Design of Nonlinear Feedback Control Systems. New York: Mc Graw-Hill, 1962.

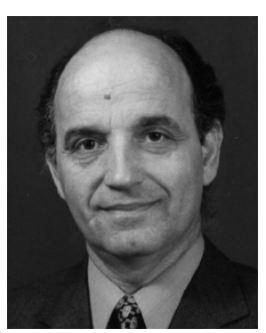

M. Aníbal Valenzuela (M'93-SM'01) received the electrical engineering degree and the Masters degree in electrical engineering from the University of Chile, Santiago, Chile, in 1976 and 1978, respectively.

Since 1978, he has been with the Department of Electrical Engineering, University of Concepción, Concepción, Chile, where he is an Associate Professor in the area of electric machines and drives. His current research interests include motion control of industrial drives, coordinated motion of multi-axis evaluation of induction motors systems, sensorless control of ac drives, and thermal

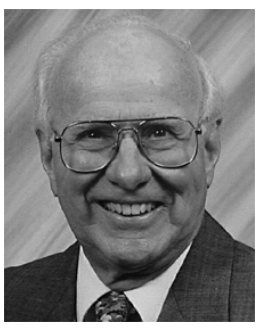

John Martin Bentley (M'54-SM'83-LS'94-LF'99) received the B.S. degree in electrical engineering from Pennsylvania State University, University Park, in 1951.

From 1951 to 1984 , he was with Westinghouse Electric Corporation, Pittsburgh, PA, and Buffalo, NY. He was awarded the company's high engineering position of Fellow, and became recognized as an authority in the field of automatic control and drive systems for the paper industry worldwide, including the first digital sectional and winder drives in North America. From 1984 to 1991, he was Principal Engineer with Allen-Bradley/Stromberg in the Milwaukee, WI, area, and was responsible for in-depth technical and marketing guidance to this multinational joint venture. During this period, he was instrumental in introducing the ac vector drive system to the North American market. Over 1000 sections, totaling approximately $200000 \mathrm{hp}$ were applied on sectional, winder, and finishing equipment drives, including the first sectional ac paper machine drive in North America. From 1991 until his retirement in 1996, he was Principal Engineer with ABB Industrial Systems Inc., New Berlin, WI, and ABB Industry OY, Helsinki, Finland. He provided application and design guidance to the worldwide ABB Pulp and Paper Systems Drives organization, primarily in the area of high-performance ac drive and control systems. He has also been an author and instructor in his areas of expertise for many years. Since his 1996 retirement from $\mathrm{ABB}$, he has continued to consult on a part-time basis, providing expertise in the areas of electromechanical influences on high-performance drive systems, cable and grounding techniques for controlling ac drive system induced common-mode currents, and general guidance for the selection and application of high performance ac drive systems.

Mr. Bentley was recognized for his professional contribution within the Technical Association of the Pulp and Paper Industry (TAPPI) through the TAPPI Engineering Division Award and the E. H. Neese Prize in 1981. A similar honor was acknowledged from the IEEE Industry Applications Society as he was a recipient of the Pulp and Paper Industry Committee Meritorious Achievement Award in 1979. He was appointed to the status of TAPPI Fellow in 1986, and in 1999 was elected as an IEEE Fellow "For contributions to the application and design of electrical drive systems in the pulp and paper industry." The Fellow status is one of the most prestigious honors bestowed by TAPPI and IEEE, and he is the only living member that has been awarded the Fellow status by both organizations. 


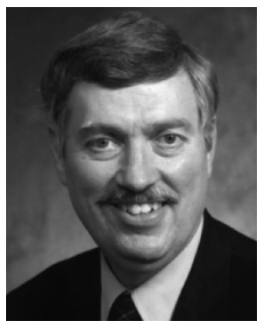

Robert D. Lorenz (S'83-M'84-SM'91-F'98) received the B.S., M.S., and Ph.D. degrees from the University of Wisconsin, Madison, and the M.B.A. degree from the University of Rochester, Rochester, NY.

Since 1984, he has been a member of the faculty of the University of Wisconsin, Madison, where he is the Mead Witter Foundation Consolidated Papers Professor of Controls Engineering in both the Department of Mechanical Engineering and the Department of Electrical and Computer Engineering. He is Co-Director of the Wisconsin Electric Machines and Power Electronics Consortium, which celebrated its 20th anniversary in 2001. It is the largest industrial research consortium on motor drives in the world. He is also the thrust leader for control and sensor integration in the Center for Power Electronic Systems, an NSF Engineering Research Center (ERC) which is a joint ERC with Virgina Polytechnic Institute and State University, Rensselaer Polytechnic Institute, University of Puerto Rico-Mayaguez, and North Carolina A\&T. From 1972 to 1982, he was a member of the research staff at the Gleason Works, Rochester, NY, working principally on high-performance drives and synchronized motion control. He was a Visiting Research Professor in the Electrical Drives Group, Catholic University of Leuven, Leuven, Belgium, in the summer of 1989 and in the Power Electronics and Electrical Drives Institute, Technical University of Aachen, Aachen, Germany, in the summers of 1987, 1991, 1995, 1997, and 1999, where he also was the SEW Eurodrive Guest Professor from September 1, 2000 until July 7, 2001. In 1969-1970, he conducted Master thesis research in adaptive control of machine tools at the Technical University of Aachen. His current research interests include sensorless electromagnetic motor/actuator technologies, real-time signal processing and estimation techniques, precision multiaxis motion control, and ac/dc drive and high-precision machine control technologies. He has authored more than 170 published technical papers and is the holder of 20 patents, with two more pending.

Dr. Lorenz is the IEEE Division II Director for 2005/2006, was the IEEE Industry Applications Society (IAS) President for 2001, a Distinguished Lecturer of the IAS for 2000/2001, immediate past Chair of the IAS Awards Department, and past Chairman of the IAS Industrial Drives Committee, and is a member of the IAS Industrial Drives, Electric Machines, Industrial Power Converter, and Industrial Automation and Control Committees. He is also the current Chair of the Periodicals Committee for the IEEE Technical Activities Board. He is a member of the IEEE Sensor Council AdCom. He was awarded the 2003 IEEE IAS Outstanding Achievement award, which honors his outstanding contributions and technological developments in the application of electricity to industry. $\mathrm{He}$ has won 17 prize paper awards. He is a Member of the American Society of Mechanical Enginees, Instrument Society of America, and The International Society for Optical Engineers. He is a Registered Professional Engineer in the States of New York and Wisconsin. 